\title{
PERILAKU KONSUMEN MASYARAKAT SURABAYA DALAM PEMBELIAN PAKAIAN
}

\author{
Felicia Goenawan $^{1 *}$, Vita Monica $^{2}$ \\ ${ }^{1,2}$ Fakultas Ilmu Komunikasi Universitas Kristen Petra \\ Jalan Siwalankerto 121-131, Surabaya \\ Email: ${ }^{1 *}$ felicia@peter.petra.ac.id; ${ }^{2}$ vita.monica@peter.petra.ac.id \\ *Penulis korespondensi
}

\begin{abstract}
ABSTRAK
Penelitian ini bertujuan untuk mengetahui bagaimana perilaku konsumen masyarakat Surabaya dalam membeli pakaian. Penelitian ini menggunakan teori perilaku konsumen, segmentasi pasar yakni demografi dan psikografi. Teori pengambilan keputusan yang digunakan hanya menggunakan tahap Problem Recognition, Information Search, dan Outlet Selection \& Purchase. Penelitian ini menggunakan metode kuantitatif, dan jenis penelitian deskriptif. Teknik sampling yang digunakan nonprobability sampling, yaitu Purposive Sampling dengan 100 responden masyarakat Surabaya serta melakukan pembelian produk fashion dalam 3 bulan terakhir. Hasil dalam penelitian ini didapati teman, majalah dan instagram merupakan media utama untuk melakukan penyebaran informasi. Iklan diskon dan iklan mode terbaru juga merupakan stimulus untuk responden melakukan pembelian ditempat.
\end{abstract}

Kata kunci: Perilaku konsumen, media, komunikasi mode.

\begin{abstract}
This study aims to determine how Surabaya's consumer behaviour in buying clothes. This study uses the theory of consumer behaviour, market segmentation, (demography and psychography). The decision-making theory used only uses the Problem Recognition, Information Search, and Outlet Selection \& Purchase stages. This research uses quantitative methods, and descriptive research type. The sampling technique used nonprobability sampling, and purposive sampling with 100 respondents who purchasing fashion product in the last 3 months. The results in this study found friends, magazines and Instagram are the main media for disseminating information. Discount ads and the latest fashion ads are also stimuli for respondents to make purchases on the spot.
\end{abstract}

Keywords: Consumer behaviour, fashion communication.

\section{PENDAHULUAN}

Perusahaan yang memproduksi produk maupun jasa, baik industrial goods maupun consumer goods, semua perlu melakukan proses komunikasi produknya kepada konsumen. Setelah memiliki produk hal lain yang perlu dipikirkan oleh perusahaan adalah harga dari produk tersebut, tempat dimana akan dipasarkan dan dibuat. Dan yang terpenting adalah promosi, dimana komunikasi sangat berperan penting dalam menyampaikan informasi bahkan mengajak atau mempersuasi calon konsumen untuk melakukan tindakan yang diinginkan oleh perusahaan.

Dalam usahanya untuk berkomunikasi dengan khalayak, perusahaan dapat menerapkan konsep Komunikasi pemasaran yang terintegrasi. Dimana konsep ini merupakan alat utama dalam perusahaan mengkomunikasikan mereknya kepada khalayak. (Sandra, Moriarty, Mitchell, \& Wells, 2015, p. 58).
Dalam menyampaian pesan dari perusahaan atau korporat kepada konsumen atau komunikan, diperlukan proses komunikasi yang tepat pada target sasaran. Dalam konteks komunikasi, penyampaian pesan dapat menggunakan media maupun nonmedia, hal ini sama dalam komunikasi pemasaran dimana istilah ini menjadi komunikasi bermedia dan komunikasi nonmedia. Penyampaian pesan melalui media ini sangat perlu diperhatikan karena setiap media memiliki karakteristik tersendiri.

Proses komunikasi dimulai dengan komunikator menyampaikan pesan menggunakan channel atau media ke komunikan. Dalam mengkomunikasikan pesan, komunikator dapat menggunakan media yang sesuai dengan situasi dan kondisi komunikan. Yang paling penting perlu dipertimbangkan apakah komunikan dapat menerima pesan tersebut dengan menggunakan media yang dipilih oleh komunikator. Luasnya lingkup pengalaman dan pengetahuan dari pelaku 
komunikasi dapat mempengaruhi proses penyampaian simbol (Kennedy \& Soemanagara, 2006);

The field of Consumer behaviour covers a lot of ground: It is the study of the process involve when individuals or group select, purchase, use, or dispose of product, services, ideas, or experiences to satisfy needs and desires. (Solomon, 2015, p. 28)

Melalui teori ini dapat dilihat bahwa mempelajari perilaku dari konsumen perusahaan merupakan langkah yang dapat digunakan oleh perusahaan untuk memahami konsumen atau bahkan calon konsumen. Bukan hanya itu hal ini akan memiliki dampak bagaimana perusahaan mengambil keputusan dalam menentukan strategi komunikasi perusahaan kedepannya. Mempelajari perilaku konsumen dalam menggunakan media untuk mencari informasi dirasa sangat perlu.

Menurut ketua APPBI Jatim Sutandi penjualan ritel fashion dari luar negeri di Surabaya berhasil mengalami pertumbuhan sekitar 8-15 persen dibanding tahun sebelumnya. (Suryanto, 2019) (Suryanto, Daya beli naik, Ritel Fashion Asing di Jatim Tumbuh 15 Persen, 2019)

Berita ini menunjukkan bahwa daya belanja masyarakat Jawa Timur lebih pada pengeluaran akan pakaian. Dengan banyaknya merek pakaian dari dalam dan luar negri serta berbagai macam media yang digunakan sebagai alat untuk menyampaikan informasi, maka akan terjadi kerancuan dan kebingungan dalam memori calon konsumen. Overload information merupakan hal yang harus dihindari oleh seseorang komunikator, karena hal ini akan berdampak pada efektifitas pesan. Hal yang dapat dilakukan oleh perusahaan untuk menghindari ini adalah dengan membuat pesan yang tepat terhadap komunikan.

Penelitian terdahulu yang dilakukan oleh S. Vijayalakshmi dan V. Mahalakshmi, terhadap konsumen di Chennai (India), impact dari perilaku membeli konsumen dalam proses pengambilan keputusan untuk produk elektronik rumah tangga. Didalam penelitian ini menguji teori Consumer Behavior Model milik Hawkins dan menggunakan metode survey dan regresi berganda. Ditemukan bahwa faktor sosial faktor fisik, dan marketing mix element memiliki pengaruh yang kuat dalam perilaku pembelian untuk konsumen India. (Vijayalakshmi \& Mahalakshmi, 2013)

Jika pada penelitian terdahulu ditemukan bahwa faktor sosial, faktor fisik, dan marketing mix yang telah dikelola oleh perusahaan memunculkan efek terhadap perilaku pembelian produk, maka hal ini menjadi menarik untuk diteliti pada konteks pengambilan keputusan untuk produk fashion di masyarakat Surabaya.

Karena itu, dengan memahami karakteristik komunikan akan membantu komunikator dalam mengelola pesan dan menyampaikan pesan yang efektif.

Tujuan dari penelitian ini adalah untuk mengetahui perilaku konsumen dari masyarakat Surabaya dalam melalui proses pengambilan keputusan pemilihan produk fashion. Hal ini nantinya akan bermanfaat untuk pelaku bisnis fashion di Surabaya dalam menggunakan media dalam berkomunikasi serta menciptakan pesan agar efektif sampai kepada komunikan dengan mempertimbangkan tahapan yang dilalui oleh komunikan dalam mengambil keputusan.

\section{TINJAUAN PUSTAKA}

\subsection{Integrated Marketing Communication (IMC)}

Definisi IMC: Is a communication process that entails the planning, creation, integration, and implementation of diverse forms of marcom (advertisements, sales prmotoions, publicity releases, events, etc.) that are delivered over time to a brand's targeted customers and prospects. (Shimp, 2010, p. 10)

Tujuan dari program IMC ini sendiri adalah untuk mempengaruhi atau mengajak adanya perubahan perilaku pada target audience. Dalam proses ini maka perusahaan harus memulai memahami konsumen atau prospek dimulai dengan tipe pesan dan penggunaan media agar dapat menginformasikan, mempengaruhi dan mendorong kecenderungan untuk bertindak. (Shimp, 2010, p. 10).

Dengan memahami bagaimana seorang konsumen mengambil sebuah keputusan untuk melakukan tindakan, maka komunikator harus memahami tahapan dalam pengambilan keputusan konsumen.

\subsection{Decision Making}

Dalam proses konsumen mengambil keputusan, ada 2 bagian yang sangat penting, yakni proses itu sendiri dan factor yang mempengaruhi proses itu. Dalam bukunya yang berjudul "Retail Management: A Strategic Approach", Berman, Evans, dan Chatterjee (2018), menyatakan bahwa terdapat enam langkah dalam proses pengambilan keputusan, yaitu stimulus, problem awareness, information search, evaluation of 
alternative, purchases, dan post-purchase behaviour. Demografi dan gaya hidup seseorang juga akan memiliki pengaruh terhadap proses tersebut.

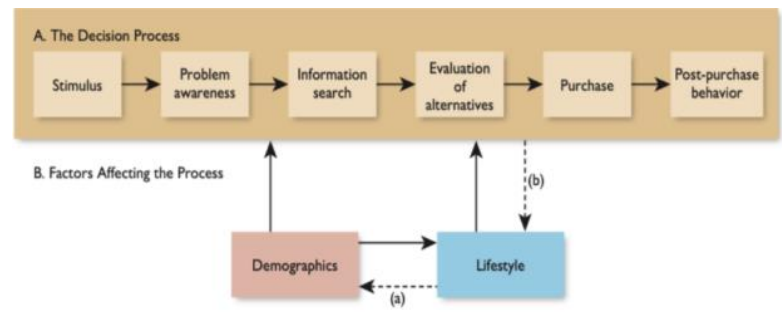

Gambar 1. Proses Pengambilan Keputusan Konsumen (Berman, Evans, \& Chatterjee, 2018, p. 201)

1. Stimulus adalah tanda (sosial atau komersial) atau dorongan (fisik) yang memotivasi atau menggerakan seseorang untuk bertindak. Ketika seseorang berbicara dengan teman, rekan kerja, atau orang lain, isyarat tersebut diterima.

2. Problem Awarenes, bukan hanya dengan lingkungan social, komersial, dan stimulus fisik tetapi konsumen menyadari bahwa produk tersebut merupakan pemenuhan atas kebutuhan.

3. Information Search, setelah konsumen mengenali masalah tersebut, mereka akan mencari informasi.

4. Evaluation of alternatives, konsumen akan memilih dari pilihan yang ada. Kriteria dalam membuat keputusan terhadap atribut barang/jasa menjadi sangat dipertimbangkan. Bisa meliputi harga, kualitas, ketersediaan, dan sebagainya.

5. Purchase, konsumen siap melakukan tindakan pertukaran uang atas produk/ jasa. Hal ini dapat meliputi tempat pembelian (place of purchase), harga dan metode pembayaran (Purchase terms), dan ketersediaan (Availability).

6. Post-Purchase behaviour, terbagi menjadi dua ketegori, yakni pembelian ulang atau evaluasi pembelian sebelumnya.

Setiap tahap dalam proses pengambilan keputusan ini adapalah tahap yang sangat penting, tetapi ada dua komponen yang bersentuhan langsung dengan kualitas komunikasi pemasaran terintegrasi, yakni Information Search dan Evaluation of alternative. (Clow \& Baack, 2007, p. 63)

Seperti dalam penelitian terdahulu yang dilakukan oleh S. Vijayalakshmi dan V. Mahalakshmi, terhadap konsumen di Chennai (India), bahwa faktor sosial, faktor fisik dan faktor marketing mix.

Teori serupa disampaikan oleh Hawkins, Best dan Coney, dalam bukunya "Consumer Behavior: Building Marketing Strategy" (2013) bahwa keputusan konsumen merupakan hasil dari masalah yang dirasakan dan kesempatan untuk pemenuhan.
Didalam tahapan Decision Process terdapat Problem Recognition, Information Search, Alternative Evaluation and Selection, Outlet Selection and Purchase, Post purchase Processes.

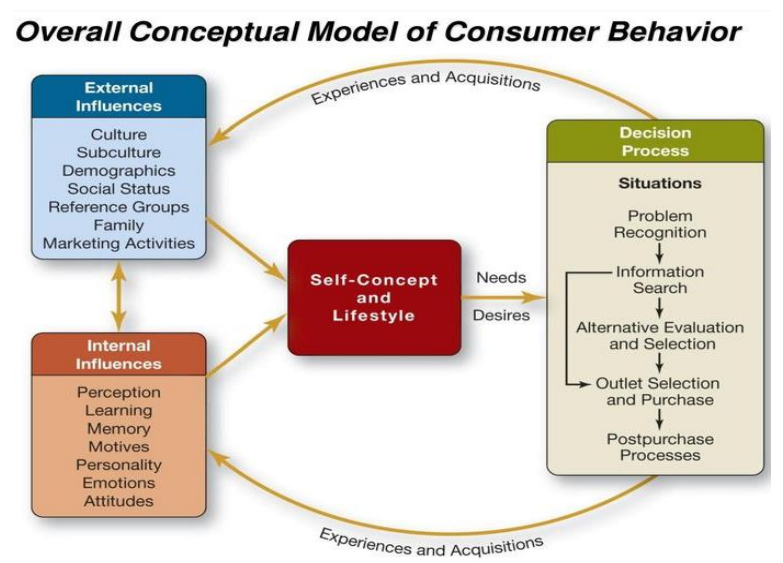

(Hawkins, Best, \& Coney, 2013, p. 25)

\subsection{Perilaku Konsumen}

Perilaku konsumen didefinisikan sebagai aktivitas tanggung jawab ketika mendapatkan mengkonsumsi, dan pembuangan produk dan jasa.

Definisi perilaku konsumen:

The field of consumer behavior is the study of individuals, groups, or organizations and the process they use to select, secure, use, and dispose of products, services, experiences, or ideas to satisfy needs and the impacts that these processes have on the consumer and society. (Hawkins, Best, \& Coney, 2013, p. 6)

Definisi perilaku konsumen yang lain:

Consumer behavior is defined as activities people undertake when obtaining, consuming, and disposing of products and services. (Blackwell, Miniard, \& Engel, 2012, p. 4)

The field of Consumer behavior covers a lot of ground: It is the study of the process involve when individuals or group select, purchase, use, or dispose of product, services, ideas, or experiences to satisfy needs and desires. (Solomon, 2015, p. 28)

Dari dua definisi yang diatas dapat diartikan bahwa perilaku konsumen adalah studi yang mempelajari individu, kelompok maupun organisasi dalam proses pemilihan, penggunaan maupun keputusan untuk tidak memakai produk, jasa maupun ide sebagi bagian dalam pemenuhan keinginan dan sebagai proses yang terjadi di individu maupun masyarakat. 
Konsumen melakukan sebuah tindakan pembelian dan terpengaruh untuk melakukannya tidak hanya dari keluarga dan teman, iklan dan role models, tetapi juga mood, situasi dan emosi (Schiffman \& Kanuk, 2007).

Salah satu cara untuk memahami pasar adalah melalui segmentasi pasar. Definisi Segmentasi Pasar:

“... Divides total markets into smaller clusters of possible customers who display similar characteristics, wants, and needs." (Rath, Petrizzi, \& Gill, 2012, p. 166)

Pasar Konsumen ini dipilah menjadi 4 kategori segmentasi, yakni Demographic, Geographic, psychographic, dan Usage. (Rath, Petrizzi, \& Gill, 2012, p. 167).

\subsubsection{Demographic Segmentation}

Segmentasi berdasarkan demografi membagi konsumen berdasarkan usia, jenis kelamin, etnis, pendapatan, pekerjaan, status pernikahan, ukuran keluarga, dan tempat tinggal (geographical location). Untuk melihat kesamaan dalam satu kelas sosial ada tiga variable demografi yang perlu diperhatikan, yakni pendapatan (income), pendidikan (education), dan pekerjaan (occupation). (Schiffman \& Kanuk, 2007, p. 57)

\subsubsection{Psychographics Segmentation}

Lifestyle yang sering disebut sebagai psychographics, dimana hal ini melibatkan aktivitas (activity), ketertarikan (interest), dan opini konsumen (opinion). (Schiffman \& Kanuk, 2007, p. 63). Schiffman \& Kanuk, memaparkan bahwa tidak ada standarisasi yang spesifik dalam mendefinisikan dimensi psychographic, hal ini dikarenakan istilah psychographic dapat digunakan pada studi yang sangat spesifik. Walaupun demikian psychographic bersama dengan demographic banyak digunakan untuk melihat framework segmentasi pasar.

Dalam penelitian ini akan digunakan 2 kategori segmentasi, yakni Demographic dan Psychographic. Hal ini dikarenakan demographic dan psychographic merupakan faktor yang memiliki dampak dalam proses pengambilan keputusan seorang konsumen seperti yang di sampaikan oleh Berman.

\section{METODE PENELITIAN}

Penelitian ini adalah penelitian deskriptif dengan pendekatan kuantitatif dan menggunakan metode survei.
Dengan metode survei, data dari sampel suatu populasi yang diteliti akan dikumpulkan menggunakan kuesioner (Effendi \& Tukiran, 2012). Sample dalam penelitian ini adalah masyarakat Surabaya yang berjumlah 100 orang. Dalam penelitian deskriptif, yaitu sekurang-kurangnya 100 sample atau $10 \%$ dari populasi. (Ruslan, 2003).

Data primer, yaitu data yang dikumpulkan dan diolah sendiri oleh suatu organisasi atau perorangan langsung dari objeknya. (Santoso, 2001)). Dalam hal ini peneliti menggunakan kuesioner sebagai instrumennya.

Kerangka sampling yang digunakan adalah NonProbability Sampling. Teknik yang tidak memberikan peluang (kesempatan) yang sama bagi setiap unsurunsur atau anggota populasi untuk dipilih menjadi sample (Ruslan, 2003).

Penelitian ini memakai Non-Probability Sampling karena jumlah populasi yang tidak diketahui dengan pasti. Teknik yang di gunakan dalam penelitian ini adalah Purposive Sampling. Participants are selected because of a particular characteristic and are therefore more likely to know others who share the same characteristic (Merrigan \& Huston, 2004).

Total sample yang digunakan adalah 100 responden yang memiliki karakteristik Berdomisili di Surabaya dan sekitarnya serta pernah melakukan pembelian produk fashion dalam 3 bulan terakhir. Pembagian kuesioner dilakukan pada bulan Maret - Mei 2019.

\section{HASIL DAN PEMBAHASAN}

\subsection{Data Responden}

Dalam penelitian ini dibagikan 100 kuesioner dan dari hasil yang dikumpulkan terdapat responden dengan jenis kelamin perempuan sebanyak 52 orang (52\%) dan laki-laki sebanyak 48 orang (48\%). Seperti data yang tercatat di Badan Pusat Statistik Kota Surabaya, per tahun 2019 proyeksi jumlah penduduk perempuan (1.465.207 jiwa) lebih banyak di banding laki-laki (1.430.988 jiwa) (Proyeksi Penduduk Kota Surabaya Menurut Jenis Kelamin dan Kelompok Usia Tahun 2019, 2021). Hal ini menunjukkan bahwa Surabaya merupakan pasar yang potensial dalam bisnis fashion. Menurut Danu Wicaksana, Managing Director Berrybenka, bahwa perempuan memiliki frekuensi berbelanja yang lebih banyak di bandingkan laki-laki. (Senja, 2017) 
Tabel 1. Data Responden berdasarkan Jenis Kelamin

\begin{tabular}{lcr}
\hline \multicolumn{3}{c}{ Jenis Kelamin Responden } \\
\hline Laki-Laki & 48 & $48 \%$ \\
Perempuan & 52 & $52 \%$ \\
\hline Total & 100 & $100 \%$ \\
\hline
\end{tabular}

Mayoritas responden berusia 17-25 tahun yaitu sebanyak 62 orang (62\%), 26-35 tahun sebanyak 20 orang (20\%), 36-45 tahun sebanyak 12 orang (12\%) dan di atas 45 tahun sebanyak 6 orang $(6 \%)$.

Tabel 2. Data Responden berdasarkan Usia

\begin{tabular}{lrr}
\hline & Usia Responden & \\
\hline $17-25$ tahun & 62 & $62 \%$ \\
$26-35$ tahun & 20 & $20 \%$ \\
$36-45$ tahun & 12 & $12 \%$ \\
$>45$ tahun & 6 & $6 \%$ \\
\hline Total & 100 & $100 \%$ \\
\hline
\end{tabular}

Tabel 3. Data Responden berdasarkan status pernikahan

\begin{tabular}{lcr}
\hline \multicolumn{3}{c}{ Status Pernikahan Responden } \\
\hline Belum Menikah & 69 & $69 \%$ \\
Menikah & 29 & $29 \%$ \\
Duda/Janda & 2 & $2 \%$ \\
\hline Total & 100 & $100 \%$ \\
\hline
\end{tabular}

Responden yang belum menikah akan memiliki peluang yang banyak dalam melakukan pengeluaran untuk kebutuhan pribadi.

\subsection{Data Responden Demographic}

Schiffman \& Kanuk dalam bukunya berjudul Customer Behaviour menjabarkan bahwa hal variabel penting dalam segmentasi demographic untuk dapat melihat sebuah kelas sosial terdiri pendapatan/ penghasilan, pendidikan dan pekerjaan.

Tabel 4. Data Responden berdasarkan Penghasilan

\begin{tabular}{lcc}
\hline \multicolumn{3}{c}{ Pendapatan per Bulan Responden } \\
\hline$<2.000 .000$ & 42 & $42 \%$ \\
$2.000 .001-5.000 .000$ & 33 & $33 \%$ \\
$5.000 .001-10.000 .000$ & 13 & $13 \%$ \\
$>10.000 .000$ & 12 & $12 \%$ \\
\hline Total & 100 & $100 \%$ \\
\hline
\end{tabular}

Tabel 5. Data Responden berdasarkan Pekerjaan

\begin{tabular}{lrr}
\hline \multicolumn{3}{c}{ Pekerjaan Responden } \\
\hline Pelajar/mahasiswa & 56 & $56 \%$ \\
Pegawai Swasta & 19 & $19 \%$ \\
Pegawai Negeri & 0 & $0 \%$ \\
Wirausaha & 10 & $10 \%$ \\
Ibu Rumah Tangga & 11 & $11 \%$ \\
Profesional & 3 & $3 \%$ \\
Lain-lain & 1 & $1 \%$ \\
\hline Total & 100 & $100 \%$ \\
\hline
\end{tabular}

Seperti yang disebutkan Burhan Bungin (Bungin, 2011) dalam Komunikasi dibalik Busana, menyebutkan dasar pembentukan kelas sosial adalah kekayaan, ukuran kepercayaan, besaran kekuasaan, ukuran kehormatan, ukuran ilmu pengetahuan dan pendidikan. (Sihabuddin, 2020, p. 49).

Tabel 6. Data Responden berdasarkan Pendidikan Terakhir

\begin{tabular}{lcr}
\hline \multicolumn{3}{c}{ Pendidikan Terakhir Responden } \\
\hline SMA / Sederajat & 59 & $59 \%$ \\
S1 & 39 & $39 \%$ \\
S2 & 2 & $2 \%$ \\
S3 & 0 & $0 \%$ \\
\hline Total & 100 & $100 \%$ \\
\hline
\end{tabular}

\subsubsection{Psychographic}

Dalam penelitian ini detemukan bahwa gaya hidup yang dimilki oleh responden menghabiskan dibawah 500.000 rupiah dalam melakukan charity (sumbangan untuk kepentingan sosial) dalam satu bulan. Dibandingkan dengan table 7 pendapatan perbulan terbanyak pendapatan perbulan terbanyak dibawah 2 juta perbulan (42\%) dan dua jutah sampai lima juta (33\%), gaya hidup untuk charity ini menjadi cukup besar. Pemilihan produk Limited Edition bagi responden bukan menjadi bagian yang terutama (78\%). Cara kita berpakaian akan merepresentasikan diri, sehingga mereka juga harus berpenampilan sesuai dengan kebutuhan yang akan diharapkan. Busana yang dikenakan merupakan presentasi dirinya agar dikenal sesuai dengan yang diinginkan maka masyarakat akan menghargai dirinya sesuai degan yang ditampilkan. (Sihabuddin, 2020, p. 87)

Tabel 7. Data responden berdasarkan jumlah uang yang dikeluarkan untuk kegiatan charity

\begin{tabular}{lcc}
\hline \multicolumn{3}{c}{ Charity Per Bulan Responden } \\
\hline$<500.000$ & 68 & $68 \%$ \\
$500.000-1.000 .000$ & 20 & $20 \%$ \\
$>1.000 .000$ & 12 & $12 \%$ \\
\hline Total & 100 & $100 \%$ \\
\hline
\end{tabular}

Tabel 8. Data Responden yang pernah melakukan pembelian produk Fashion Limiten Edition

\begin{tabular}{lcc}
\hline & Responden pernah Membeli Limited Edition \\
\hline Ya & 22 & $22 \%$ \\
Tidak & 78 & $78 \%$ \\
\hline Total & 100 & $100 \%$ \\
\hline
\end{tabular}

\subsection{Proses Pengambilan Keputusan}

Didalam penelitian ini proses pengambilan keputusan yang akan diteliti adalah pencarian informasi dan Evaluasi of Alternative. 


\subsubsection{Pencarian Informasi}

Setelah proses mengetahui bahwa responden memilki kebutuhn terhadap produk fashion, langkah selanjutnya adalah dengan mencari informasi. Ini adalah proses dimana komunikasi perusahaan kepada calon konsumen mulai menjadi perhatian, apakah perusahaan menyediakan informasi dan menggunakan media yang dibutuhkan oleh konsumen sehingga komunikasi menjadi efektif. Hanya 47\% responden yang mencari informasi sebelum mereka melakukan pembelian.

Tabel 9. Responden mencari Informasi sebelum melakukan Pembelian

\begin{tabular}{lcc}
\hline \multicolumn{3}{c}{ Responden yang Mencari informasi Sebelum Membeli } \\
\hline Ya & 47 & $47 \%$ \\
Tidak & 53 & $53 \%$ \\
\hline Total & 100 & $100 \%$ \\
\hline
\end{tabular}

Tabel 10. Responden Mencari Informasi melalui Orang lain

\begin{tabular}{lcc}
\hline \multicolumn{3}{c}{ Responden yang Mencari Informasi melalui } \\
\hline Ya & 48 & $48 \%$ \\
Tidak & 52 & $52 \%$ \\
\hline Total & 100 & $100 \%$ \\
\hline
\end{tabular}

Jumlah responden yang melalui orang lain sebagai referensi adalah $48 \%$. Salah satu karakteristik remaja adalah penyesuaian diri dan penyesuaian sosial sangat dipengaruhi oleh sikap teman sebaya terhadap pakaian, maka sebagaian besar remaja berusaha keras untuk menyesuasikan diri dengan apa yang dikehendaki kelompok dalam hal berpakaian. (Hurlock, 1980, p. 220). Adapan referensi itu didapan dari teman (46\%), keluarga (44\%), dan rekan kerja (10\%). Konsep diri seseorang juga ditentukan oleh kelompok rujukannya. (Sihabuddin, 2020, p. 104)

Salah satu media yang digunakan oleh perusahaan dalam memberikan informasi terkait produk fashion adalah media massa. Sebanyak $26 \%$ responden melalukan pencarian informasi terkait produk fashion, yakni melalui alternative media (38\%), majalah (19\%), Surat kabar (19\%), televisi (15\%), dan radio (8\%). Hal ini disebabkan karena sifat tradisional media jangkauan yang luas dan tidak spesifik. (Yeshin, 1998, p. 175)

Media internet / New Media menjadi pilihan 59\% responden dalam pencarian informasi. Media Instagram (78\%), website (10\%), dan Facebook (7\%). Hal ini dikarenakan perkembangan teknologi yang saat ini mengikuti perkembangan generasi. Media Instagram dapat digunakan untuk memberikan informasi me- lalui gambar di feed, caption yang dpaat memberikan detail informasi terkait produk, dan media Instagram merupakan salah satu media yang banyak diakses oleh remaja. Seperti yang diriis oleh CNN Indonesia, We Are Social 2020 menemukan waktu rata-rata yang digunakan oleh pengguna usia 16-64 dalam mekakses media sosial mencapai 3 jam dan 26 enit per hari. Salah satunya adalah Instagram dan Facebook. (Ikhsan , 2020)

Tabel 11. Responden pernah melakukan pembelian tak terduga

\begin{tabular}{lcc}
\hline \multicolumn{2}{c}{ Responden pernah melakukan } & \multicolumn{3}{c}{ Pembelian } & Tidak & Terduga \\
\hline Ya & 69 & $69 \%$ \\
Tidak & 31 & $31 \%$ \\
\hline Total & 100 & $100 \%$ \\
\hline
\end{tabular}

Selain media massa dan new media, media below the line juga memiliki dampak dalam melakukan penyebaran informasi, bahkan sampai responden melakukan tindakan.

$69 \%$ responden pernah melakukan tindakan pembelian tidak terduga dikarenakan diskon toko (52\%), display model terbaru di toko (29\%), dan komunikasi dengan Sales Promotion di toko (9\%). Kemampuan berkomunikasi persuasi menjadi salah satu hal perlu diperhatikan oleh komunikator dalam mengkomunikasikan dan memberikan informasi terkait produk dan jasa.

\subsubsection{Evaluation of Alternative}

Ini adalah tahap dimana responden melibatkan atribut barang/jasa dalam pengambilan keputusan. Ini dapat meliputi harga, kualitas, keterlihatan, ketersediaan dan sebagainya. (Berman, Evans, \& Chatterjee, 2018, p. 202).

Tabel 12. Cara responden melakukan pembelian

\begin{tabular}{lcr}
\hline \multicolumn{3}{c}{ Cara responden melakukan pembelian } \\
\hline On Store & 69 & $69 \%$ \\
Online & 25 & $25 \%$ \\
Versi Online dari Store & 5 & $5 \%$ \\
other & 1 & $1 \%$ \\
\hline Total & 100 & $100 \%$ \\
\hline
\end{tabular}

Tabel 13. Tempat Responden melakukan pembelian

\begin{tabular}{lrr}
\hline \multicolumn{3}{c}{ Tempat responden melakukan pembelian } \\
\hline Departement Store & 38 & $38 \%$ \\
Discount Store & 5 & $5 \%$ \\
Specialty Store & 31 & $31 \%$ \\
Online Shop & 24 & $24 \%$ \\
other & 2 & $2 \%$ \\
\hline Total & 100 & $100 \%$ \\
\hline
\end{tabular}


Tabel 14. Cara responden melakukan pembarayan

\begin{tabular}{lrr}
\hline \multicolumn{3}{c}{ Cara responden melakukan Pembayaran } \\
\hline Tunai & 67 & $67 \%$ \\
Kartu Kredit & 14 & $14 \%$ \\
Cicilan & 3 & $3 \%$ \\
Transfer & 15 & $15 \%$ \\
other & 1 & $1 \%$ \\
\hline Total & 100 & $100 \%$ \\
\hline
\end{tabular}

Dalam penelitian ini ditemukan bahwa kualitas (33\%), banyaknya pilihan yang disediakan (29\%), mudah di temukan barang tersebut (20\%), serta sudah berlangganan (loyal) (13\%). Hal ini merupakan alasan bahwa $38 \%$ responden melakukan pembelian di department store, serta 69\% responden lebih menyukai belanja On store. Hal ini terjadi karena adanya kemudahan konsumen melakukan pembelian dalam area yang sama (cross-shopping) dan banyak dari konsumen yang ingin melakukan penghematan waktu dan biaya perjalanan. (Berman, Evans, \& Chatterjee, 2018, pp. 201-202).

Berman, Evans, \& Chatterjee mengatakan bahwa tempat untuk melakukan pembelian akan dijadikan salah satu pertimbangan yang akan dievaluasi, layaknya barang dan jasa yang di jual. Tepat yang paling diharapkan akan dipilih oleh konsumen. (2018, p. 202).

Cara pembayaran merupakan salah satu yang menjadi perhatian dalam proses evaluasi alternative. Ditemukan dalam penelitian ini $67 \%$ responden lebih memilih pembayaran tunai, $15 \%$ transfer, dan $14 \%$ menggunakan kartu kredit. Purchase Terms meliputi harga dan metode dalam pembayaran. Metodhe pembayang yang paing dipilih oleh responden adalah pembayaran tunai.

\section{KESIMPULAN}

Dalam melakukan pembelian produk fashion, komunikasi merupakan hal terpenting dalam menyampaikan pesan kepada calon konsumen. Dengan memahami latar belakang komunikan melalui demographic dan psychographic.

Dalam proses pengambilan keputusan teman dan keluarga memiliki peranan penting dalam memberikan masukan. Majalah dan Instagram merupakan media untuk mendapatkan informasi produk-produk. Budaya pembelian Onstore merupakan pilihan utama oleh responden. Hal ini tentu disertai dengan cara pembayaran tunai masih menjadi pilihan pertama. Sebagai komunikator, iklan diskon dan iklan model terbaru menjadi stimulus untuk responden mengambil tindakan pembelian di tempat. Hal yang menarik ditemukan dalam penelitian ini adalah cara responden dalam mencari informasi banyak menggunakan new media yakni Instagram, website dan facebook. Sedangkan untuk tempat melakukan pembelian hal yang dipertimbangkan justru onstore didampingi dengan cara pembayaran tradisional yakni secara tunai.

\section{DAFTAR PUSTAKA}

Kotler, P. (1997). Manajemen Pemasaran: Analisis, Perencanaan, Implementasi, dan Kontrol, Jilid 1, Edisi Bahasa Indonesia. Jakarta: PT. Prehallindo.

Kennedy, J. E., \& Soemanagara, R. D. (2006). Marketing Communication: Taktik \& Strategi. Jakarta Barat: PT. Bhuana Ilmu Populer.

Suryanto. (2019, Maret 5). Daya beli naik, Ritel Fashion Asing di Jatim Tumbuh 15 Persen. Retrieved from Radar Surabaya.id: https://radarsurabaya.jawapos.com/read/2019/03/05/123235/ daya-beli-naik-ritel-fashion-asing-di-jatimtumbuh-15-persen

Effendi, S., \& Tukiran. (2012). Metode Penelitian Survei. Jakarta: LP3ES.

Ruslan, R. (2003). Metode Penelitian Public Relations dan Komunikasi. Jakarta: PT. Raja Grafindo Persada.

Santoso, S. (2001). Riset Pemasaran konsep dan aplikasi dengan SPSS. Jakarta: PT. Elex media Komputindo.

Merrigan, G., \& Huston, C. L. (2004). Communication Research Methods. United Stated of America: Thomson Learning Wadsworth.

Suryanto. (2019, Maret 5). Daya beli naik, Ritel Fashion Asing di Jatim Tumbuh 15 Persen. Retrieved from Radar Surabaya.id: https://radarsurabaya.jawapos.com/read/2019/03/05/123235/ daya-beli-naik-ritel-fashion-asing-di-jatimtumbuh-15-persen

Schiffman, L. G., \& Kanuk, L. L. (2007). Consumer Behavior. New Jersey: Pearson Prentice Hall International Edition.

Hawkins, D., Best, R., \& Coney, K. (2013). Consumer Behavior: Building Marketing Strategy, Twelfth Edition. New York: The McGraw-Hill Companies, Inc.

Blackwell, R. D., Miniard, P. W., \& Engel, J. F. (2012). Consumer Behavior. Singapore: Cengage Learning Asia Pte Ltd.

Solomon, M. R. (2015). Cunsumer Behavior: Buying, Having, and Being. Eleventh Edition. Edinburgh Gate: Pearson Education Limited. 
Rath, P. M., Petrizzi, R., \& Gill, P. (2012). Marketing Fashion: A Global Perspective. New York: Bloomsbury Publising Inc.

Vijayalakshmi, S., \& Mahalakshmi, V. (2013). An impact of consumer buying behavior in decision making process in purchase of electronic home appliances in Chennai (India): an empirical study. Elixir Marketing Management 59.

Sandra, Moriarty, S., Mitchell, N., \& Wells, W. (2015). Advertising \& IMC: Principles and Parctice (Vol. Tenth edition). (S. Wall, Ed.) Edinburgh Gate, Harlow, England: Pearson Education Limited.

Shimp, T. A. (2010). Advertising, Promotion, and other aspects of Integrated Marketing Communication (Vol. Eighth Edition). South-Western: Cengage Learning.

Berman, B., Evans, J. R., \& Chatterjee, P. (2018). Retail Management: A Strategic Approach (Vol. Thirteenth Edition). Harlow, United Kingdom: Pearson Education Limited.

Clow, K. E., \& Baack, D. (2007). Integrated Advertising, Promotion, and Marketing Communication (Vol. 3 edition). New Jersey: Prentice Haall.

Proyeksi Penduduk Kota Surabaya Menurut Jenis Kelamin dan Kelompok Usia Tahun 2019.
(2021). Retrieved from Badan Pusat Statistik Kota Surabaya: https://surabayakota.bps.go.id/ dynamictable/2018/04/18/23/proyeksi-pendu duk-kota-surabaya-menurut-jenis-kelamin-dankelompok-umur-tahun-2019.html

Senja, A. M. (2017, Januari 30). Wanita Lebih Sering Belanja ketimbang Pria, tetapi ... Retrieved from Kompas.com: https://lifestyle.kompas.com/read/ 2017/01/30/150300520/wanita.lebih.sering.bela nja.ketimbang.pria.tetapi.

Hurlock, E. B. (1980). Psikologi Perkembangan: Suatu Pendekatan Sepanjang Rentang Kehidupan. Jakarta: Penerbit Erlangga.

Yeshin, T. (1998). Integrated Marketing Communication: The Holistic Approach. Oxford: Butterworth Heinemann.

Ikhsan , M. (2020, Agustus 27). Survey: 5 Media Sosial Paling Populer di Dunia. Retrieved Februari 2021, from CNN Indonesia: https://www. cnnindonesia.com/teknologi/20200819154002185-537377/survei-5-media-sosial-palingpopuler-di-dunia

Sihabuddin. (2020). Komunikasi di Balik Busana. Yogyakarta: Arruzz Media. 